\title{
Prognostic Value of DEPDC1 Expression in Tumor and Non-tumor Tissue of Patients With Hepatocellular Carcinoma
}

\author{
MASATAKA AMISAKI, TAKUKI YAGYU, EI UCHINAKA, MASAKI MORIMOTO, TAKEHIKO HANAKI, \\ JOJI WATANABE, NARUO TOKUYASU, TERUHISA SAKAMOTO, SOICHIRO HONJO and YOSHIYUKI FUJIWARA \\ Division of Surgical Oncology, Department of Surgery, Tottori University Faculty of Medicine, Tottori, Japan
}

\begin{abstract}
Background/Aim: To evaluate the impact of DEPDCl expression on patient prognosis after hepatic resection for hepatocellular carcinoma (HCC). Patients and Methods: We reviewed data from 75 patients who underwent hepatic resection for HCC between 2004 and 2013. Recurrence at 2 years following resection, which mainly included metastatic recurrence, was defined as late recurrence. Results: DEPDC1 was up-regulated in HCC tissue and in non-tumor tissue of patients with $\mathrm{HCC}$ compared to normal liver ( $p<0.01$ and $p<0.01$, respectively). High expression of DEPDCl was associated with poor overall, disease-specific, and disease-free survival ( $p=0.02$, $p<0.01$, and $p<0.01$, respectively). High DEPDC1 expression was an independent predictor of death and recurrence ( $p=0.03$ and $p<0.01$, respectively). High expression of DEPDCl in non-tumor liver was an independent risk factor for late recurrence $(p=0.04)$. Conclusion: High expression of DEPDC1 in tumor tissue appears to be associated with tumor progression and poor prognosis.
\end{abstract}

Hepatocellular carcinoma (HCC) is one of the most common cancers globally, and the third most common cause of cancer-related death $(1,2)$. Hepatic resection is a curative therapeutic option for patients with $\operatorname{HCC}(3,4)$, although high tumor recurrence is observed in $60-70 \%$ of cases within 5 years after surgery, resulting in poor patient prognosis $(5-$ 7). Therefore, the identification of novel factors for prevention of recurrence of HCC may lead to improved therapeutic approaches and patient prognosis.

Correspondence to: Masataka Amisaki, Division of Surgical Oncology, Department of Surgery, School of Medicine, Tottori University Faculty of Medicine, 36-1 Nishi-cho, Yonago, Tottori 683-8503, Japan. Tel: +81 859386567, Fax: +81 859386569, e-mail: amisakim@tottori-u.ac.jp

Key Words: DEPDC1, risk factor, liver surgery.
The DEP domain containing 1 (DEPDC1) protein has been shown to be up-regulated in several malignancies, including HCC (8-10). Furthermore, the DEPDC1-ZNF224 complex has been shown to repress the transcription of the A20 gene, resulting in translocation of the NF-kB protein into the nucleus where it suppresses apoptosis in cancer cells (11). A recent study by Qu et al. using The Cancer Genome Atlas (TCGA) gene expression dataset (cancergenome.nih.gov/) showed that high expression of DEPDC1 in patients with HCC was associated with a poor prognosis (12). Furthermore, we discovered that DEPDC1 could be detected not only in tumor tissues, but also slightly in non-tumor liver of some HCC patients as shown in our preliminary data of immunohistochemistry staining using anti-DEPDC1 antibody (Figure 1). Since HCC can arise in non-tumor liver with some degree of damage, we hypothesized that DEPDC1 is related not only to tumor malignancy, but also to tumorigenesis of HCC. In the present study, we analyzed the prognostic value of DEPDC1 expression in tumor and non-tumor liver using quantitative real-time PCR (qPCR) data from tissue samples of patients with HCC.

\section{Patients and Methods}

Patients. Liver specimens from 75 patients with HCC and 10 patients with benign liver tumors were obtained at the Tottori University Hospital between 2004 and 2013, and immediately stored in RNAlater ICE (Thermo Fisher Scientific, Waltham, MA, USA) at $-80^{\circ} \mathrm{C}$. Patient clinical data including survival were collected from medical records. Disease recurrence was identified by either computed tomography or magnetic resonance imaging. Patients with histologically diagnosed HCC who underwent initial and curative resection were included in this study. Criteria for surgery included the following factors: Eastern Cooperative Oncology Group (ECOG) performance status <3, preserved liver function estimated from both indocyanine green test and volumetric computed tomography, and good general condition without serious organ failure. Non-anatomical resection was performed in patients estimated to have insufficient volume of remnant liver or who had tumors located peripherally. Intraoperative temporary inflow clump and transfusion were 
performed on demand according to the decision of the consulting surgeon and/or anesthesiologist.

The use of tissue samples for immunohistochemistry and reverse transcription-polymerase chain reaction (RT-PCR) and the reviewing of medical records were approved by the Institutional Review Board of our institution in accordance with the ethical standards laid down in the 1964 Declaration of Helsinki and its later amendments (Institutional Review Board approval number: 1606A029, 1610A118, and 18A071).

Immunohistochemistry staining. For immunohistochemical staining (Figure 1), samples of two patients different from the cohort for real-time PCR were used. Formalin-fixed paraffin-embedded tissue specimens were cut into $4-\mu \mathrm{m}$ sections. After dewaxing in xylene, tissue sections were autoclaved for $10 \mathrm{~min}$ in citrate buffer, preincubated in $0.3 \% \mathrm{H}_{2} \mathrm{O}_{2}$, and blocked for $20 \mathrm{~min}$ using diluted normal blocking serum from a VECTASTAIN Elite ABC HRP kit (Vector Laboratories, Inc., Burlingame, CA, USA). Sections were incubated with 1:100 diluted anti-DEPDC1 antibody (ab197246, Abcam, Cambridge, UK) as a primary antibody followed by a HRPconjugated secondary antibody (Vector Laboratories). DEPDC1 protein was visualized using ImmPACT DAB substrate (Vector Laboratories) with a reaction time of $4.5 \mathrm{~min}$.

RNA extraction and quantitative RT-PCR. RNA from frozen specimens was recovered and purified using TRIzol reagent Thermo Fisher Scientific) and a RNeasy Plus Kit (QIAGEN, Hilden, Germany) according to the manufacturer's instructions. Total RNA was converted into complementary DNA (cDNA) using Super Script II reverse transcriptase (Thermo Fisher Scientific) with random 6-mer primers. cDNA was then subjected to RT-PCR analysis with Universal Probe Library probes using a FastStar PCR Master Mix premixed with ROX (Roche, Basel, Switzerland) on a ViiA7 system (Thermo Fisher Scientific) under the following conditions: $50^{\circ} \mathrm{C}$ for $2 \mathrm{~min}, 95^{\circ} \mathrm{C}$ for $10 \mathrm{~min}$, and 40 cycles of $95^{\circ} \mathrm{C}$ for $15 \mathrm{sec}$ and $60^{\circ} \mathrm{C}$ for $1 \mathrm{~min}$. The primers and probes used were as follows: DEPDC1-forward, cctatggagagtcagggtgtg; DEPDC1reverse, cgaaaagatgtggtaacttcattc; probe for DEPDC1, probe \#49; beta-actin (ACTB)-forward, attggcaatgagcggttc; ACTB-reverse, ggatgccacaggactcca; probe for ACTB, probe \#11; 18 ribosomal RNA (18rRNA)-forward, ccgattggatggtttagtgag; 18rRNA-reverse, agttcgaccgtcttctcagc; probe for 18rRNA, probe \#81. Relative mRNA expression levels were represented as fold changes and normalized against the expression of the ACTB housekeeping gene, except for mRNA from tumor tissue in which ACTB is de-regulated and 18 rRNA is used as a housekeeping gene (13).

Other variables. Data collected included patient characteristics (age, sex, BMI, comorbidity, cause of hepatitis, Child-Pugh score, Model for End-Stage Liver Disease (MELD) score, retention rate of injected indocyanine green at $15 \mathrm{~min}$ (ICG-R15), serum creatinine, and albumin); tumor characteristics (number of tumors and maximum tumor diameter); intraoperative data (extent of resection, usage of intermittent total hepatic inflow clumping, duration of surgery, intraoperative hemorrhage volume, volume of intraoperative blood transfusion, length of hospital stay after surgical resection, and postoperative complications); and pathological findings [stage of fibrosis in adjacent liver according to the Histological Activity Index (14)]. Comorbidity of cardiovascular disease was identified when patients had a history of angina pectoris or chronic heart failure. Major resection was defined as hepatectomy of more than two Couinaud segments.

Statistical analysis. All quantitative values are presented as median and interquartile range (Table I). Statistical analysis was conducted using a chi-square test and Fisher's exact test ( $<5$ variables) for categorical variables. Welch's two-sample $t$-test and multiple comparison adjusted with Holm's method were used for continuous variables in unpaired and pairwise tests, respectively. Overall and recurrence-free survival periods were analyzed by Kaplan-Meier analysis. Values of $p<0.05$ were considered statistically significant. For multivariate analysis excluding analysis of late recurrence of HCC, factors with $p<0.05$ in univariate analysis were analyzed (Tables II and III). In the multivariate analysis of late recurrence of HCC (Table IV) in which only one factor was $p<0.05$, factors with $p<0.10$ were exceptionally included. $\mathrm{R}$ version 3.1.3 software (www.r-project.org/) was used for all statistical analyses.

\section{Results}

Seventy-five patients were included in the study. Expression of DEPDC1 in HCC tumors was higher than that in nontumor liver of HCC patients and in normal liver (Figure 2). Patients were divided into two groups according to average DEPDC1 expression levels, and the characteristics of the two groups are shown in Table I. High DEPDC1 expression was associated with high capsular invasion, high portal vein invasion, and advanced tumor stage, indicating that DEPDC1 may be associated with tumor malignancy (Table I). Overall, disease-specific, and recurrence-free survival rates were worse in the DEPDC1-high group than in the DEPDC1-low group; 5-year overall survival (OS) rates were $50.0 \%$ and $79.0 \%(p=0.016), 5$-year disease-specific survival rates were $60.0 \%$ and $88.6 \%(p=0.002)$, and 5 -year recurrence -free survival rates were $26.0 \%$ and $43.7 \%(p<0.001)$ in DEPDC1-high and -low group, respectively (Figure 3). Multivariate analysis revealed that high expression of DEPDC1 in HCC was independently associated with poor OS (HR=3.007, 95\%CI=1.092-8.282, $p=0.033$; Table II) and poor recurrence-free survival $(\mathrm{HR}=3.374,95 \% \mathrm{CI}=1.632$ 6.979, $p=0.004$; Table III), with statistical significance.

We subsequently analyzed the expression of DEPDC1 in non-tumor liver of HCC patients and found that it was highly expressed compared with that in the liver of non-HCC patients (Figure 2). We therefore hypothesized that DEPDC1 may promote tumorigenesis in the residual liver of HCC patients following curative resection. Next, patients were divided into two groups according to DEPDC1 expression in non-tumor liver tissue, using a cutoff value of 6.87 as determined by the mean $+2 *$ SD expression of DEPDC 1 in normal liver. DEPDC1 overexpression in non-tumor liver correlated with high ICG-R15 and MELD score (Figure 4A and 4B), indicating that DEPDC1 was highly expressed in damaged and cirrhotic liver. Given that HCC recurrence within 2 years after hepatic resection is primarily attributable 

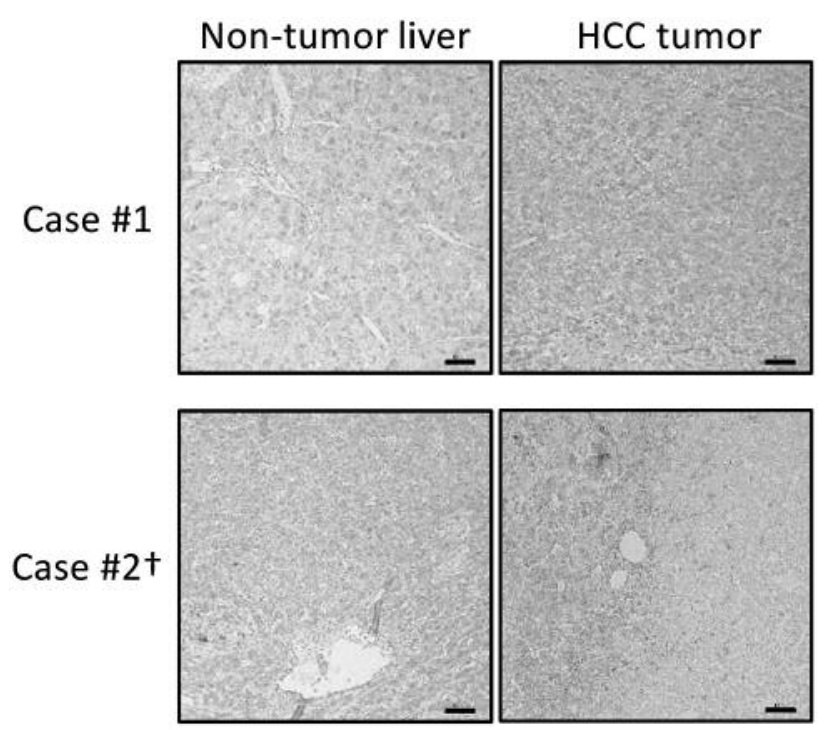

Figure 1. Representative immunohistochemistry images of tissue samples from HCC patients stained using an anti-DEPDC1 antibody. Case \#1: HCC tumor moderately expressed DEPDC1 and non-tumor liver was negative for DEPDC1 expression. Case \#2: weak DEPDC1 expression observed in non-tumor liver and tumor. ${ }^{\dagger}$ More than $90 \%$ of tumor tissue in case \#2 was necrotic. Scale bar: $50 \mu \mathrm{m}$.

to intrahepatic metastasis from resected HCC (15), we focused on late recurrence that occurred more than 2 years after resection to determine the impact of DEPDC1 expression on de novo recurrence of $\mathrm{HCC}$ from residual liver. As demonstrated in Figure 5A, compared with normal expression of DEPDC1, up-regulated expression of DEPDC1 was associated with a lower recurrence-free survival rate in patients with $\mathrm{HCC} \quad(\mathrm{HR}=2.575,95 \% \mathrm{CI}=1.036-6.403$, $p=0.042$ for the Cox proportional hazards model; $p=0.030$ for Kaplan-Meier analysis). Overall recurrence-free survival rates were not affected by DEPDC1 expression status in nontumor liver (Figure 5B). Furthermore, with the exception of DEPDC1, other clinical factors had no influence on late recurrence of HCC (Table IV).

\section{Discussion}

Our findings confirmed that DEPDC1 was up-regulated in patients' HCC tissue compared to their own non-tumor liver, and patients whose HCC tissue had higher expression of DEPDC1 had poorer prognosis after curative resection. Furthermore, DEPDC1 expression was slightly elevated in non-tumor liver tissue of HCC patients compared with normal liver tissue. Overexpression of DEPDC1 in residual liver may therefore lead to late recurrence of $\mathrm{HCC}$, which was previously thought to arise primarily de novo.
Table I. Patient characteristics.

\begin{tabular}{|c|c|c|c|}
\hline & $\begin{array}{c}\text { High } \\
\text { DEPDC1 }\end{array}$ & $\begin{array}{c}\text { Low } \\
\text { DEPDC1 }\end{array}$ & $p$-Value \\
\hline Number of patients & 21 & 54 & \\
\hline Age $(y)$ & $68[65-73]$ & $72[63.3-75]$ & 0.267 \\
\hline \multicolumn{4}{|l|}{ Gender } \\
\hline Male/ Female & $17 / 4$ & $46 / 8$ & 0.922 \\
\hline BMI & $\begin{array}{c}21.1 \\
{[20.0-23.1]}\end{array}$ & $\begin{array}{c}22.4 \\
{[21.2-24.6]}\end{array}$ & 0.100 \\
\hline \multicolumn{4}{|l|}{ Etiology } \\
\hline $\mathrm{HBV} / \mathrm{HCV} / \mathrm{NBNC}$ & $26 / 9 / 20$ & $8 / 7 / 6$ & 0.285 \\
\hline Bilirubin $(\mathrm{mg} / \mathrm{dl})$ & $0.60[0.50-0.90]$ & $0.60[0.50-0.78]$ & 0.711 \\
\hline Albumin (g/dl) & $3.8[3.5-4.1]$ & $4.0[3.7-4.3]$ & 0.579 \\
\hline $\operatorname{AFP}(n g / m l)$ & $60.0[6.4-467.3]$ & $5.6[3.0-16.8]$ & 0.018 \\
\hline \multicolumn{4}{|l|}{ Child-Pugh score } \\
\hline $5 / 6 / 7 / 8$ & $14 / 6 / 0 / 1$ & $43 / 8 / 3 / 0$ & 0.136 \\
\hline MELD score & $8[7-8]$ & $7[7-8]$ & 0.041 \\
\hline \multicolumn{4}{|l|}{ Extent of resection } \\
\hline Major & 5 & 18 & 0.579 \\
\hline Non-anatomical & 9 & 15 & 0.272 \\
\hline Operative duration (min) & 368 [278-555] & 400 [331-489] & 0.521 \\
\hline $\begin{array}{l}\text { Intraoperative blood } \\
\text { loss }(\mathrm{ml})\end{array}$ & $\begin{array}{c}360 \\
{[220-695]}\end{array}$ & $\begin{array}{c}432.5 \\
{[220-913.8]}\end{array}$ & 0.641 \\
\hline \multicolumn{4}{|l|}{ Number of tumors } \\
\hline $1 / 2 / \geq 3$ & $14 / 6 / 1$ & $46 / 8 / 0$ & 0.064 \\
\hline Tumor size $(\mathrm{cm})$ & $3.0[2.2-5.0]$ & $3.8[2.5-6.0]$ & 0.460 \\
\hline $\begin{array}{l}\text { Capsular invasion } \\
+/-\end{array}$ & $20 / 1 / 0$ & $34 / 14 / 4$ & 0.027 \\
\hline \multicolumn{4}{|l|}{ Septum formation } \\
\hline $\begin{array}{l}+/- \\
\text { Serosal invasion }\end{array}$ & $14 / 6$ & $31 / 18$ & 0.782 \\
\hline $\begin{array}{l}\text { Serosal invasion } \\
+/-\end{array}$ & $8 / 13$ & $12 / 37$ & 0.263 \\
\hline \multicolumn{4}{|l|}{ Portal vein invasion } \\
\hline \multicolumn{3}{|l|}{ Hepatic vein invasion } & 1.000 \\
\hline \multicolumn{4}{|l|}{ TNM stage } \\
\hline \multicolumn{3}{|l|}{ Fibrosis stage } & 0.046 \\
\hline $0 / 1 / 2 / 3 / 4$ & $3 / 6 / 3 / 3 / 6$ & $13 / 5 / 6 / 16 / 11$ & 0.931 \\
\hline
\end{tabular}

BMI: Body mass index; AFP: alfa-fetoprotein; MELD: Model for EndStage Liver Disease; TNM: TNM Classification of Malignant Tumors; HBV: hepatitis B; HCV: hepatitis C; NBNC: negative for HCV and HBsAg.

Recent studies have shown that DEPDC1 plays an important role in the development of several malignancies. For example, DEPDC1 has been shown to activate NF-kB and E2F signaling pathways to accelerate cell cycle progression $(10,16)$, and to promote the K-RAS and WNT/b-catenin signalling pathways in gene set enrichment analysis of RNA sequence data (12). These results show that DEPDC1 promotes cell-cycle progression and cell proliferation via multiple pathways related to cancer, indicating that cancer cells with a high expression of DEPDC1 may have high malignancy, resulting in poor patient prognosis. In support of 
Table II. Cox proportional hazards model for death from all causes.

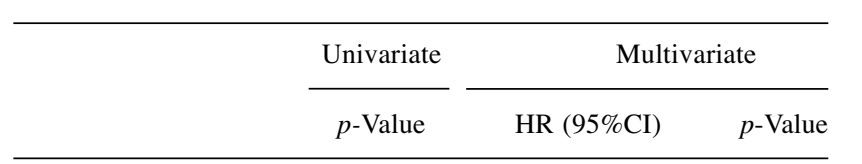

\begin{tabular}{|c|c|c|c|}
\hline \multicolumn{4}{|l|}{ Age $(y)$} \\
\hline$\geq 75 \mathrm{y}$ & 0.370 & & \\
\hline \multicolumn{4}{|l|}{ Gender } \\
\hline Male & 0.770 & & \\
\hline \multicolumn{4}{|l|}{ BMI } \\
\hline$\geq 25$ & 0.037 & $0.101(0.012-0.808)$ & 0.031 \\
\hline \multicolumn{4}{|l|}{ Etiology } \\
\hline HBV & 0.810 & & \\
\hline $\mathrm{HCV}$ & 0.190 & & \\
\hline NBNC & 0.140 & & \\
\hline \multicolumn{4}{|l|}{ AFP } \\
\hline$\geq 20 \mathrm{ng} / \mathrm{ml}$ & 0.002 & $3.122(1.171-8.319)$ & 0.023 \\
\hline \multicolumn{4}{|l|}{ Child-Pugh score } \\
\hline B & 0.100 & & \\
\hline \multicolumn{4}{|l|}{ MELD score } \\
\hline$\geq 10$ & 0.990 & & \\
\hline \multicolumn{4}{|l|}{ Extent of resection } \\
\hline Major & 0.260 & & \\
\hline Non-anatomical & 0.630 & & \\
\hline $\begin{array}{l}\text { Operative duratior } \\
\geq 8 \mathrm{~h}\end{array}$ & \multicolumn{2}{|c|}{ Operative duration } & \\
\hline \multicolumn{4}{|c|}{ Intraoperative blood loss } \\
\hline \multicolumn{4}{|l|}{ Number of tumors } \\
\hline Multiple & 0.006 & $2.848(0.699-11.596)$ & 0.144 \\
\hline \multicolumn{4}{|l|}{ Tumor size } \\
\hline $\begin{array}{l}\text { Portal vein invasi } \\
+/-\end{array}$ & 0.007 & $1.019(0.153-6.768)$ & 0.985 \\
\hline \multicolumn{3}{|l|}{ TNM stage } & 0.500 \\
\hline \multicolumn{4}{|l|}{ Fibrosis stage } \\
\hline$\geq 3$ & 0.504 & & \\
\hline \multicolumn{4}{|l|}{ DEPDC1 } \\
\hline High & 0.032 & $3.007(1.092-8.282)$ & 0.033 \\
\hline
\end{tabular}

BMI: Body mass index; AFP: alfa-fetoprotein; MELD: Model for EndStage Liver Disease; TNM: TNM Classification of Malignant Tumors; HBV: hepatitis B; HCV: hepatitis C; NBNC: negative for HCV and HBsAg.

this, increased expression of DEPDC1 was shown to be related to poor prognosis of HCC patients in a study using TCGA data (12). In the present study, we demonstrated a relationship between high DEPDC1 expression and poor prognosis in patients with HCC. Moreover, we identified DEPDC1 as a prognostic marker of HCC independent of other known clinical factors, using multivariate analysis. As expected, DEPDC1 was shown to potentially promote HCC progression, thus representing a promising therapeutic target.

As our preliminary immunohistochemistry data implied the presence of DEPDC1 in non-tumor liver, we analyzed the
Table III. Cox proportional hazards model for recurrence.

\begin{tabular}{|c|c|c|c|}
\hline & \multirow{2}{*}{$\frac{\text { Univariate }}{p \text {-Value }}$} & \multicolumn{2}{|c|}{ Multivariate } \\
\hline & & HR $(95 \% \mathrm{CI})$ & $p$-Value \\
\hline \multicolumn{4}{|l|}{ Age (y) } \\
\hline$\geq 75 \mathrm{y}$ & 0.475 & & \\
\hline \multicolumn{4}{|l|}{ Gender } \\
\hline Male & 0.151 & & \\
\hline \multicolumn{4}{|l|}{ BMI } \\
\hline$\geq 25$ & 0.790 & & \\
\hline \multicolumn{4}{|l|}{ Etiology } \\
\hline HBV & 0.736 & & \\
\hline $\mathrm{HCV}$ & 0.045 & $3.917(1.700-9.024)$ & 0.001 \\
\hline NBNC & 0.146 & & \\
\hline \multicolumn{4}{|l|}{ AFP } \\
\hline$\geq 20 \mathrm{ng} / \mathrm{ml}$ & 0.001 & $3.034(1.553-5.929)$ & 0.001 \\
\hline \multicolumn{4}{|l|}{ Child-Pugh score } \\
\hline B & 0.710 & & \\
\hline \multicolumn{4}{|l|}{ MELD score } \\
\hline$\geq 10$ & 0.682 & & \\
\hline \multicolumn{4}{|l|}{ Extent of resection } \\
\hline Major & 0.542 & & \\
\hline Non-anatomical & 0.881 & & \\
\hline \multicolumn{3}{|l|}{ Operative duration } & \\
\hline \multicolumn{4}{|l|}{ Intraoperative blood loss } \\
\hline \multicolumn{4}{|l|}{ Number of tumors } \\
\hline Multiple & 0.000 & $3.358(1.588-7.103)$ & 0.002 \\
\hline $\begin{array}{l}\text { Tumor size } \\
\geq 5 \mathrm{~cm}\end{array}$ & Tumor size & $5.165(2.251-11.809)$ & 0.000 \\
\hline \multicolumn{4}{|l|}{ Portal vein invasion } \\
\hline \multicolumn{4}{|l|}{ TNM stage } \\
\hline \multicolumn{4}{|l|}{ Fibrosis stage } \\
\hline \multicolumn{4}{|l|}{ DEPDC1 } \\
\hline High & 0.003 & $3.224(1.588-6.543)$ & 0.001 \\
\hline High in non-tumor liver & 0.464 & & \\
\hline
\end{tabular}

BMI: Body mass index; AFP: alfa-fetoprotein; MELD: Model for EndStage Liver Disease; TNM: TNM Classification of Malignant Tumors; HBV: hepatitis B; HCV: hepatitis C; NBNC: negative for HCV and HBsAg.

expression of DEPDC1 in non-tumor liver tissue samples. ICGR15 is widely used to measure liver function (17), and the MELD score is used to assess the severity of chronic liver disease (18). In the present study, high ICG-R15 levels and high MELD score were associated with high expression of DEPDC1 in non-tumor liver, indicating that the expression levels of DEPDC1 in non-tumor liver correlated with the degree of liver damage. Therefore, liver damage may up-regulate DEPDC1 expression, even in non-malignant or pre-malignant lesions.

It is widely accepted that carcinogenesis is a multistep process accelerated by the accumulation of genetic alterations 
Table IV. Cox proportional hazards model for late recurrence.

\begin{tabular}{|c|c|c|c|}
\hline & \multirow{2}{*}{$\frac{\text { Univariate }}{p \text {-Value }}$} & \multicolumn{2}{|c|}{ Multivariate } \\
\hline & & HR (95\%CI) & $p$-Value \\
\hline \multicolumn{4}{|l|}{ Age (y) } \\
\hline$\geq 75 \mathrm{y}$ & 0.955 & & \\
\hline \multicolumn{4}{|l|}{ Gender } \\
\hline Male & 0.548 & & \\
\hline \multicolumn{4}{|l|}{ BMI } \\
\hline$\geq 25$ & 0.537 & & \\
\hline \multicolumn{4}{|l|}{ Etiology } \\
\hline HBV & 0.756 & & \\
\hline $\mathrm{HCV}$ & 0.866 & & \\
\hline NBNC & 0.901 & & \\
\hline \multicolumn{4}{|l|}{ AFP } \\
\hline$\geq 20 \mathrm{ng} / \mathrm{ml}$ & 0.263 & & \\
\hline \multicolumn{4}{|l|}{ Child-Pugh score } \\
\hline $\mathrm{B}$ & 0.936 & & \\
\hline \multicolumn{4}{|l|}{ MELD score } \\
\hline$\geq 10$ & 0.956 & & \\
\hline \multicolumn{4}{|l|}{ Extent of resection } \\
\hline Major & 0.720 & & \\
\hline Non-anatomical & 0.758 & & \\
\hline \multicolumn{4}{|l|}{ Operative duration } \\
\hline $\begin{array}{l}\text { Intraoperative blood loss } \\
\geq 1,0001\end{array}$ & \multicolumn{2}{|c|}{ Intraoperative blood loss } & \\
\hline \multicolumn{4}{|l|}{ Number of tumors } \\
\hline Multiple & 0.125 & & \\
\hline \multicolumn{4}{|l|}{ Tumor size } \\
\hline$\geq 5 \mathrm{~cm}$ & 0.296 & & \\
\hline \multicolumn{4}{|l|}{ Portal vein invasion } \\
\hline $\begin{array}{l}\text { TNM stage } \\
\geq \mathrm{II}\end{array}$ & \multicolumn{2}{|c|}{ TNM stage } & \\
\hline \multicolumn{4}{|l|}{ Fibrosis stage } \\
\hline$\geq 3$ & 0.071 & $2.315(0.931-5.757)$ & 0.071 \\
\hline \multicolumn{4}{|l|}{ DEPDC1 } \\
\hline High & 0.428 & & \\
\hline High in non-tumor liver & 0.042 & $2.570(1.038-6.364)$ & 0.041 \\
\hline
\end{tabular}

BMI: Body mass index; AFP: alfa-fetoprotein; MELD: Model for EndStage Liver Disease; TNM: TNM Classification of Malignant Tumors; HBV: hepatitis B; HCV: hepatitis C; NBNC: negative for HCV and HBsAg.

and activated signaling pathways to form malignant cells (19, 20) . Prior to the development of HCC, premalignant lesions or regenerative nodules undergo changes such as promoter mutation of telomerase reverse transcriptase for telomere maintenance, the most common gene alteration in HCC (21). HCC after curative resection frequently recurs by metastasis from the primary site as well as from de novo tumorigenesis in the remnant liver $(15,22)$. It is therefore likely that damaged liver tissue at risk for carcinogenesis contains activated signaling pathways to drive the development of HCC. Therefore, therapeutic targets in the remnant liver should be

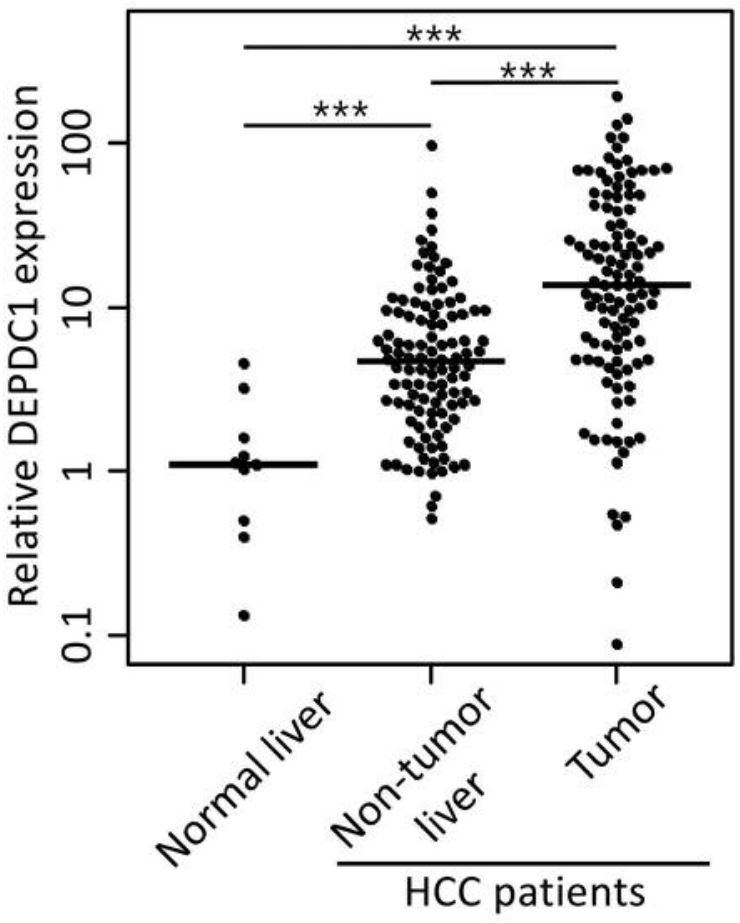

Figure 2. Relative expression level of DEPDC1 in normal liver of nonHCC patients and in non-tumor liver and tumor of HCC patients. $* * * p<0.001$.

identified to enable the development of preventative therapy after curative resection. To date, adjuvant usage of sorafenib, a promising molecular-targeting therapy for HCC, has been shown to be insufficient to prevent recurrence of HCC after curative resection (23). Moreover, although patients with low serum albumin, viral etiology, or high elevated hepatic venous pressure have been shown to be at risk of de novo development of HCC after surgery (24), few factors contributing to late recurrence have been identified. Remarkably, we found that the expression of DEPDC1 in non-tumor adjacent liver correlated with late-phase recurrence of HCC. Taken together with the correlation between DEPDC1 and liver disease, these results are consistent with the clinical observation that patients with cirrhosis have an increased risk of developing HCC (22). Thus, DEPDC1 may represent a therapeutic target to prevent recurrence of $\mathrm{HCC}$ after curative resection.

In addition, multivariate analysis for the prediction of recurrence showed that high DEPDC1 expression in tumor tissue was related to overall recurrence of $\mathrm{HCC}$, whereas high DEPDC1 in non-tumor tissue was related to late recurrence. This result clearly indicates that early recurrence was attributable to tumor factors while late recurrence was attributable to host factors such as the remnant liver. These results were consistent with clinical evidence. 

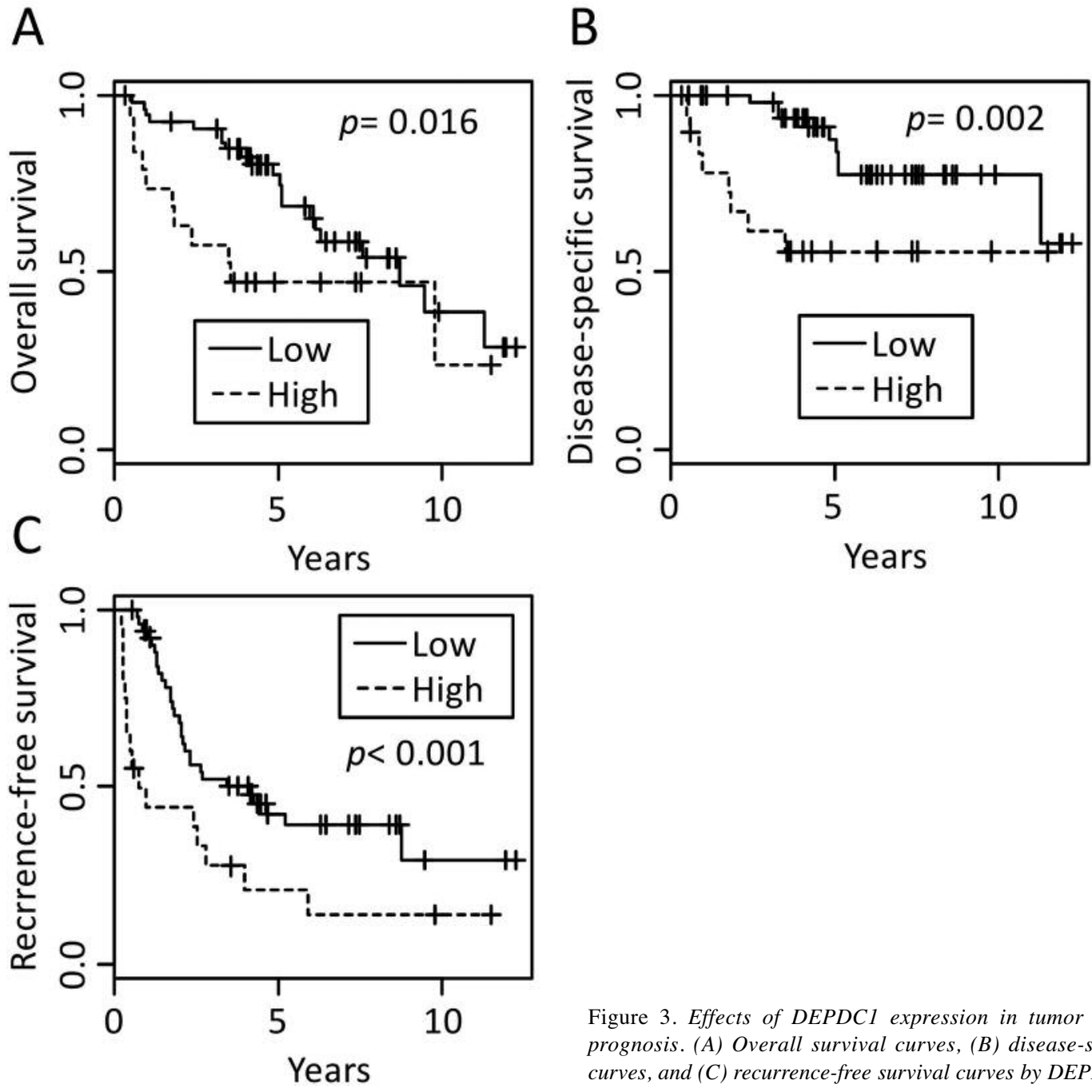

Figure 3. Effects of DEPDC1 expression in tumor tissue on HCC prognosis. (A) Overall survival curves, (B) disease-specific survival curves, and $(C)$ recurrence-free survival curves by DEPDC1 expression.

This study had several limitations. First, the study was retrospective in design and enrolled patients were not consecutive because tissue samples were unavailable for some potential participants. Additionally, the small number of enrolled patients may have contributed to selection bias. However, the study cohort had similar characteristics to those in our previous research, in which all patients were enrolled consecutively, and to those in other previous clinical studies conducted in the same geographical region $(15,25$, 26). Furthermore, a cutoff value for DEPDC1 in non-tumor liver was not established. In the present study, we used a value calculated from the upper $95 \% \mathrm{CI}$ of the expression level in normal liver to determine the high expression level in non-tumor liver. Further studies to evaluate and validate this cutoff value for the detection of up-regulation of DEPDC1 in non-tumor liver are, therefore, needed.

In conclusion, we demonstrated that DEPDC1 was upregulated in tumor and non-tumor liver tissue of patients

with HCC. Tumor DEPDC1 expression correlated with tumor malignancy and poor OS, whereas expression in nontumor liver may be related to liver damage and de novo recurrence. Our findings showed that DEPDC1 appears to be involved in the regulation of carcinogenesis and progression of $\mathrm{HCC}$ and thus represents a potential therapeutic and preventive target of HCC.

\section{Conflicts of Interest}

The Authors report no conflicts of interest regarding this study.

\section{Authors' Contributions}

M.A. designed the study. M.A., T.Y., E.U., M.M., T.H., J.W., N.T., T.S., and S.H. collected and processed samples. M.A. analyzed the data. M.A. and Y.F. wrote the article. All Authors declare they significantly participated in creation of the study. All Authors read and approved the final article 

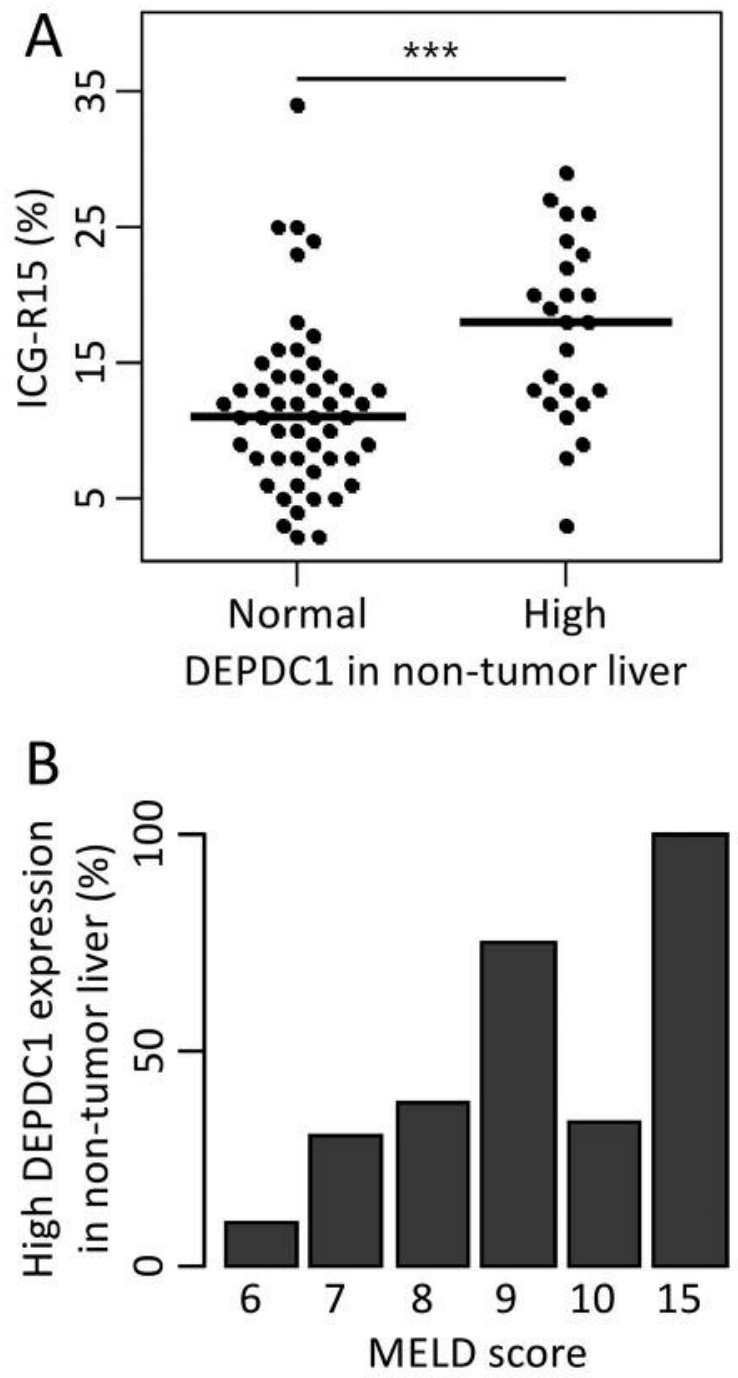

Figure 4. Relationship between DEPDC1 expression in non-tumor liver and liver damage. (A) ICG-R15 values by DEPDC1 status in non-tumor liver. (B) Percentage of patients with high DEPDC1 status in non-tumor liver for each MELD score.

\section{Acknowledgements}

The Authors would like to thank Clare Cox, PhD, from Edanz Group (www.edanzediting.com/ac) for editing a draft of this manuscript.

\section{References}

1 Forner A, Llovet JM and Bruix J: Hepatocellular carcinoma. Lancet 379(9822): 1245-1255, 2012. PMID: 22353262. DOI: 10.1016/S0140-6736(11)61347-0
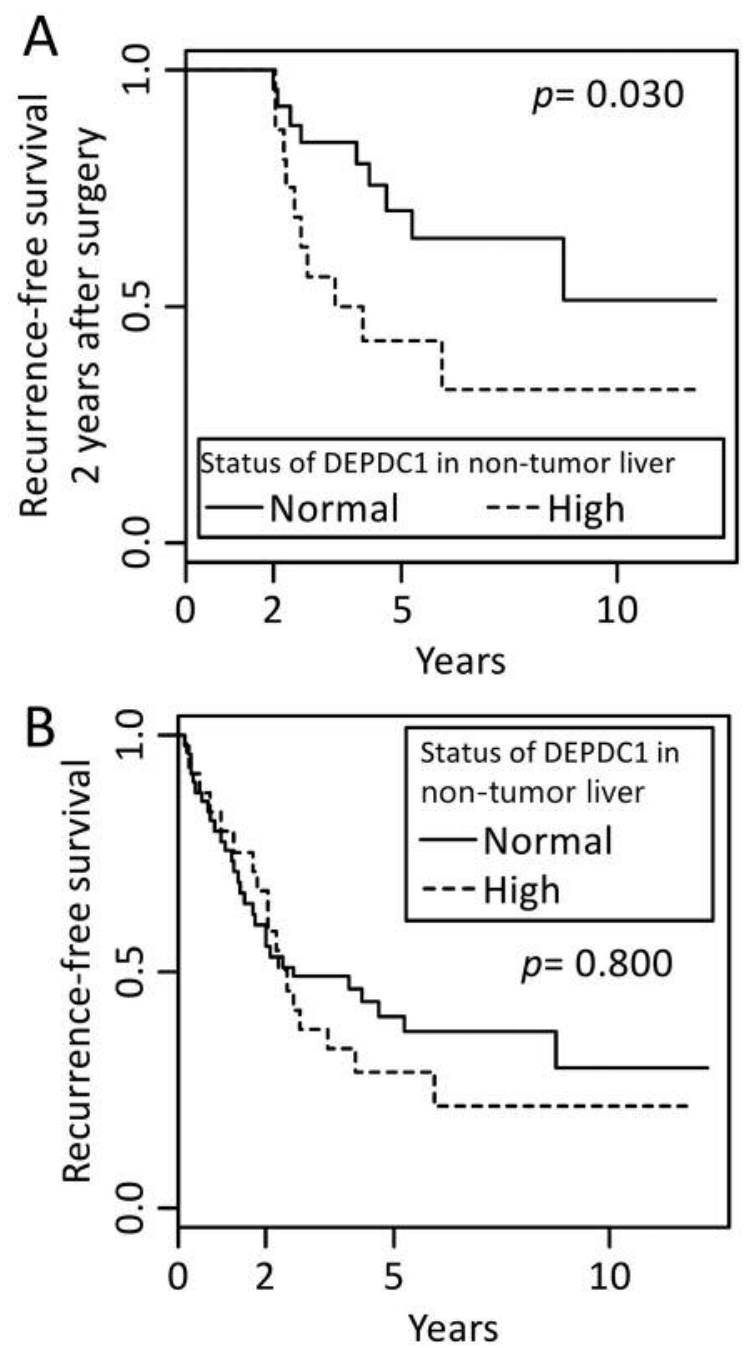

Figure 5. Effect of DEPDC1 expression in non-tumor tissue on HCC recurrence. (A) Recurrence-free survival curves 2 years after curative surgery by DEPDC1 expression in non-tumor liver. (B) Overall recurrence-free survival curves by DEPDC1 expression in non-tumor liver.

2 Jemal A, Bray F, Center MM, Ferlay J, Ward E and Forman D: Global cancer statistics. CA Cancer J Clin 61(2): 69-90, 2011. PMID: 21296855. DOI: 10.3322/caac.20107

3 Japan LCSGo: Primary liver cancer in Japan. Clinicopathologic features and results of surgical treatment. Ann Surg 211(3): 277287, 1990. PMID: 2155591.

4 Roayaie S, Jibara G, Tabrizian P, Park JW, Yang J, Yan L, Schwartz M, Han G, Izzo F, Chen M, Blanc JF, Johnson P, Kudo M, Roberts LR and Sherman M: The role of hepatic resection in the treatment of hepatocellular cancer. Hepatology 62(2): 440-451, 2015. PMID: 25678263. DOI: 10.1002/ hep. 27745 
5 Ishizawa T, Hasegawa K, Aoki T, Takahashi M, Inoue Y, Sano $\mathrm{K}$, Imamura $\mathrm{H}$, Sugawara $\mathrm{Y}$, Kokudo $\mathrm{N}$ and Makuuchi M: Neither multiple tumors nor portal hypertension are surgical contraindications for hepatocellular carcinoma. Gastroenterology 134(7): 1908-1916, 2008. PMID: 18549877. DOI: 10.1053/ j.gastro.2008.02.091

6 Belghiti J, Panis Y, Farges O, Benhamou JP and Fekete F: Intrahepatic recurrence after resection of hepatocellular carcinoma complicating cirrhosis. Ann Surg 214(2): 114-117, 1991. PMID: 1714267. DOI: $10.1097 / 00000658-199108000-00004$

7 European Association For The Study Of The Liver and European Organisation For Research And Treatment Of Cancer: EASLEORTC clinical practice guidelines: Management of hepatocellular carcinoma. J Hepatol 56(4): 908-943, 2012. PMID: 22424438. DOI: 10.1016/j.jhep.2011.12.001

8 Yuan S-G, Liao WJ, Yang JJ, Huang GJ and Huang ZQ: Dep domain containing 1 is a novel diagnostic marker and prognostic predictor for hepatocellular carcinoma. Asian Pac J Cancer Prev 15(24): 10917-10922, 2015. PMID: 25605201. DOI: 10.7314/ apjcp.2014.15.24.10917

9 Ramalho-Carvalho J, Martins JB, Cekaite L, Sveen A, TorresFerreira J, Graca I, Costa-Pinheiro P, Eilertsen IA, Antunes L, Oliveira J, Lothe RA, Henrique R and Jeronimo C: Epigenetic disruption of mir-130a promotes prostate cancer by targeting sec23b and depdc1. Cancer Lett 385: 150-159, 2017. PMID: 27984115. DOI: $10.1016 /$ j.canlet.2016.10.028

10 Feng X, Zhang C, Zhu L, Zhang L, Li H, He L, Mi Y, Wang Y, $\mathrm{Zhu} \mathrm{J}$ and $\mathrm{Bu} \mathrm{Y}$ : Depdc1 is required for cell cycle progression and motility in nasopharyngeal carcinoma. Oncotarget 8: 6360563619, 2017. PMID: 28969015. DOI: 10.18632/oncotarget. 18868

11 Harada Y, Kanehira M, Fujisawa Y, Takata R, Shuin T, Miki T, Fujioka T, Nakamura Y and Katagiri T: Cell-permeable peptide depdc1-znf224 interferes with transcriptional repression and oncogenicity in bladder cancer cells. Cancer Res 70(14): 58295839, 2010. PMID: 20587513. DOI: 10.1158/0008-5472.CAN10-0255

12 Qu D, Cui F, Lu D, Yang Y and Xu Y: Dep domain containing 1 predicts prognosis of hepatocellular carcinoma patients and regulates tumor proliferation and metastasis. Cancer Sci 110(1): 157-165, 2019. PMID: 30417471. DOI: $10.1111 /$ cas. 13867

13 Waxman S and Wurmbach E: De-regulation of common housekeeping genes in hepatocellular carcinoma. BMC Genomics 8: 243, 2007. PMID: 17640361. DOI: 10.1186/14712164-8-243

14 Ishak K, Baptista A, Bianchi L, Callea F, De Groote J, Gudat F, Denk H, Desmet V, Korb G, MacSween RN, Phillips MJ, Portmann BG, Poulsen H, Scheuer PJ, Schmid M and Thaler H: Histological grading and staging of chronic hepatitis. J Hepatol 22(6): 696-699, 1995. PMID: 7560864.

15 Imamura H, Matsuyama Y, Tanaka E, Ohkubo T, Hasegawa K, Miyagawa S, Sugawara Y, Minagawa M, Takayama T, Kawasaki S and Makuuchi M: Risk factors contributing to early and late phase intrahepatic recurrence of hepatocellular carcinoma after hepatectomy. J Hepatol 38(2): 200-207, 2003. PMID: 12547409.

16 Huang L, Chen K, Cai ZP, Chen FC, Shen HY, Zhao WH, Yang SJ, Chen XB, Tang GX and Lin X: Depde1 promotes cell proliferation and tumor growth via activation of e2f signaling in prostate cancer. Biochem Biophys Res Commun 490(3): 707712, 2017. PMID: 28634077. DOI: 10.1016/j.bbrc.2017.06.105
17 De Gasperi A, Mazza E and Prosperi M: Indocyanine green kinetics to assess liver function: Ready for a clinical dynamic assessment in major liver surgery? World J Hepatol 8(7): 355367, 2016. PMID: 26981173. DOI: 10.4254/wjh.v8.i7.355

18 Malinchoc M, Kamath PS, Gordon FD, Peine CJ, Rank J and ter Borg PC: A model to predict poor survival in patients undergoing transjugular intrahepatic portosystemic shunts. Hepatology 31(4): 864-871, 2000. PMID: 10733541. DOI: 10.1053/he.2000.5852

19 Fantini M, Benvenuto M, Masuelli L, Frajese GV, Tresoldi I, Modesti A and Bei R: In vitro and in vivo antitumoral effects of combinations of polyphenols, or polyphenols and anticancer drugs: Perspectives on cancer treatment. Int J Mol Sci 16(5): 9236-9282, 2015. PMID: 25918934. DOI: 10.3390/ijms 16059236

20 Hai H, Tamori A and Kawada N: Role of hepatitis b virus DNA integration in human hepatocarcinogenesis. World $\mathrm{J}$ Gastroenterol 20(20): 6236-6243, 2014. PMID: 24876744. DOI: 10.3748/wjg.v20.i20.6236

21 Nault JC, Mallet M, Pilati C, Calderaro J, Bioulac-Sage P, Laurent C, Laurent A, Cherqui D, Balabaud C and ZucmanRossi J: High frequency of telomerase reverse-transcriptase promoter somatic mutations in hepatocellular carcinoma and preneoplastic lesions. Nat Commun 4: 2218, 2013. PMID: 23887712. DOI: $10.1038 /$ ncomms 3218

22 Fattovich G, Stroffolini T, Zagni I and Donato F: Hepatocellular carcinoma in cirrhosis: Incidence and risk factors. Gastroenterology 127(5): S35-S50, 2004. PMID: 15508101.

23 Bruix J, Takayama T, Mazzaferro V, Chau GY, Yang J, Kudo M, Cai J, Poon RT, Han KH, Tak WY, Lee HC, Song T, Roayaie S, Bolondi L, Lee KS, Makuuchi M, Souza F, Berre MA, Meinhardt $G$ and Llovet JM: Adjuvant sorafenib for hepatocellular carcinoma after resection or ablation (storm): A phase 3, randomised, double-blind, placebo-controlled trial. Lancet Oncol 16(13): 1344-1354, 2015. PMID: 26361969. DOI: 10.1016/S1470-2045(15)00198-9

24 Ripoll C, Groszmann RJ, Garcia-Tsao G, Bosch J, Grace N, Burroughs A, Planas R, Escorsell A, Garcia-Pagan JC, Makuch R, Patch D, Matloff DS and Portal Hypertension Collaborative Group: Hepatic venous pressure gradient predicts development of hepatocellular carcinoma independently of severity of cirrhosis. J Hepatol 50(5): 923-928, 2009. PMID: 19303163. DOI: $10.1016 /$ j.jhep.2009.01.014

25 Wu J, Du J, Liu L, Li Q, Rong W, Wang L, Wang Y, Zang M, Wu Z, Zhang Y and Qu C: Elevated pretherapy serum il17 in primary hepatocellular carcinoma patients correlate to increased risk of early recurrence after curative hepatectomy. PLoS One 7(12): e50035, 2012. PMID: 23227158. DOI: 10.1371/ journal.pone.0050035

26 Amisaki M, Yagyu T, Uchinaka E, Morimoto M, Tokuyasu N, Sakamoto T, Honjo S, Saito H and Fujiwara Y: Impact of postoperative mean arterial pressure on the incidence of postoperative complications after hepatic resection for primary liver malignancy. Surg Today 49(6): 488-497, 2019. PMID: 30637514. DOI: $10.1007 /$ s00595-019-1759-7

Received June 27, 2019

Revised July 3, 2019

Accepted July 4, 2019 